Plant Tissue Cult. \& Biotech. 20(1): 7-12, 2010 (June)



\title{
Micropropagation of Marsdenia brunoniana Wight \& Arn. - A rare antidiabetic plant
}

\author{
A. Ugraiah, S. Karuppusamy ${ }^{1}$ and T. Pullaiah \\ Department of Botany, Sri Krishnadevaraya University, Anantapur-515 003, \\ Andhra Pradesh, India
}

Key words: Marsdenia brunoniana, Medinal plant, Micropropagation, Conservation

\begin{abstract}
Shoot multiplication of M. brunoniana Wight \& Arn. was achieved from the nodal explants of mature plants using MS with different concentrations and combinations of growth regulators. Maximum explant response and highest number of shoots per explant was obtained on MS medium fortified with $1.0 \mathrm{mg} / \mathrm{l} \mathrm{BAP}$. The highest degree of shoot proliferation was found to be $90 \%$. The combination of $\mathrm{BAP}$ and $\mathrm{Kn}$ was also found to be effective for regeneration. The regenerated shoots were successfully rooted on MS supplemented with $0.5 \mathrm{mg} / \mathrm{l}$ NAA, after sequential hardening; survival rate was $90 \%$.
\end{abstract}

\section{Introduction}

The genus Marsdenia of the family Asclepiadaceae consists of 100 species distributed throughout tropical countries. In India it is represented by 13 species as reported by Jagtap and Singh (1999). Marsdenia contains many chemical compounds like two polyoxypregnanes, designated marstenacigenins $\mathrm{A}$ and $\mathrm{B}$ (Sheng-Xiang et al. 1996) and polyhydroxy pregnane ester named tenasogenin in M. tenacissima (Singhal et al. 1980). Marsdenin, is a glycoside isolated from $M$. erecta $\mathrm{R}$. Br. (Baytop et al. 1959). Most of them have medicinal value. $M$. brunoniana is one such rare medicinal twining shrub found in Tamilnadu and Karnataka states of Peninsular India (Natarajan 2004). The leaves of the plant have been extensively used for the treatment of diabetes (Kottaimuthu 2008). Conventionally this plant is propagated through the seeds. Natural population of the plant species is decreasing due to habitat destruction, overexploitation along with poor seed setting and poor seed germination. There have been no reports on in vitro propagation of M. brunoniana. Hence the in vitro

${ }^{1}$ Department of Botany, The Madura College, Madurai, Tamil Nadu, India. $<$ ugramilin2007@gmail.com>. 
propagation of this medicinally important species was undertaken. The present study describes the maximization of shoot multiplication through in vitro propagation of M. brunoniana by using standard culture medium fortified with different growth regulators.

\section{Materials and Methods}

Shoots of two-month-old plants of Marsdenia brunoniana grown in the Botanical Garden of Sri Krishnadevaraya University were selected as explants. The leaves and roots were discarded and shoots were washed thoroughly under running tap water $(20 \mathrm{~min})$. Nodal portion was used as an explant. They were then treated $(15 \mathrm{~min})$ with two drops of aqueous surfactant - Tween $20(5 \% \mathrm{v} / \mathrm{v})$ for 5 min, followed by repeated rinsing with distilled water. Further, sterilization was done under aseptic conditions in laminar air flow cabinet. Explants were surface sterilized with $50 \%(\mathrm{v} / \mathrm{v})$ ethyl alcohol $(1 \mathrm{~min})$ followed by $0.1 \%(\mathrm{w} / \mathrm{v}) \mathrm{HgCl}_{2}(3$ $\mathrm{min}$ ). Finally, the explants were washed thoroughly (five times) with sterilized distilled water and cut into appropriate size $(1 \mathrm{~cm})$ and inoculated on sterilized medium. MS was used with $3 \%(\mathrm{w} / \mathrm{v})$ sucrose and gelled with $0.8 \%(\mathrm{w} / \mathrm{v})$ agaragar. The $\mathrm{pH}$ of all media was adjusted to 5.8 and sterilized by autoclave at $121^{\circ} \mathrm{C}$ for $15 \mathrm{~min}$. The cultures were incubated at $25 \pm 1^{\circ} \mathrm{C}$ under a $16 \mathrm{hr}$ photoperiod $\left(50 \mu / \mathrm{E}^{2} / \mathrm{s}\right.$ irradiance) provided by cool white fluorescent tubes. Various plant growth regulators viz., BAP $(0.5-5 \mathrm{mg} / \mathrm{l}), \mathrm{Kn}(0.5-5 \mathrm{mg} / \mathrm{l})$ and NAA, IAA, IBA $(0.25-2 \mathrm{mg} / \mathrm{l})$ were tried individually or in combination to obtain the multiple shoot bud induction. Observations were recorded at an interval of four weeks. For root induction, in vitro microshoots with six fully expanded leaves were excised and transferred to half strength MS semisolid medium supplemented with NAA $(0.5 \mathrm{mg} / \mathrm{l})$. Roots were initiated after the fifth day of inoculation in the medium containing $0.5 \mathrm{mg} / \mathrm{l} \mathrm{NAA}$ and fully profuse roots developed after three weeks. Rooted micro-shoots were thoroughly washed to remove the adhering gel and planted in $5 \mathrm{~cm}$ plastic cups containing a mixture of peat moss and organic manure $(1: 1)$. Plastic cups were covered with polythene bags to maintain humidity. Plants were kept in culture room for ten days. Half strength MS macro salts was poured to the plastic cups at five-day regular intervals until the new leaves developed. Plants were transferred to pots containing organic manure, garden soil and forest humus $(1: 1: 1)$. The pots were watered at a two-day interval and were maintained in greenhouse. The survival rate was recorded one month after transfer to pots. All experiments were repeated at least three times with ten replicates for each treatment. 


\section{Results and Discussion}

Nodal explants were cultured on MS fortified with different concentrations of BAP and $\mathrm{Kn}$ individually and also in combinations for multiple shoot bud induction and data have been presented in Table 1. Nodal buds when cultured on MS with different concentrations of BAP $(0.5-5.0 \mathrm{mg} / \mathrm{l})$, produced maximum number of shoots on the medium containing $1 \mathrm{mg} / \mathrm{l}$ of BAP within six weeks of incubation, with an average length of $3 \mathrm{~cm}$ (Fig. 1A). Increase or decrease in the concentration of BAP beyond the optimum level, a smaller number of shoot buds. These results are in agreement with earlier findings of Ramasubbu et al. (2009) in Pedalium murex and Physalis angulata, however in the present findings the length of shoots increased. During subculture, basal axillary buds of the developed axillary buds also underwent initiation. Enhanced shoot multiplication in subsequent culture is in accordance with published literature on Asclepiadacean medicinal plants like Gymnema sylvestre (Komavalli and Rao 2000), Hemidesmus indicus (Sreekumar et al. 2000) and Holostemma ada-kodien (Martin 2002). However, in Hemidesmus indicus (Patnaik and Debata 1996) repeated subcultures do not enhance shoot proliferation.

Table 1. Effect of concentrations of BAP and Kn on bud breaking and multiple shoot induction from nodal explants of M. brunoniana.

\begin{tabular}{ccccc}
\hline $\begin{array}{l}\text { BAP } \\
(\mathrm{mg} / \mathrm{l})\end{array}$ & $\begin{array}{c}\mathrm{Kn} \\
(\mathrm{mg} / \mathrm{l})\end{array}$ & \% response & $\begin{array}{c}\text { No. of shoots } \\
(\text { Mean } \pm \mathrm{SE})\end{array}$ & $\begin{array}{c}\text { Shoot length in cm } \\
(\text { Mean } \pm \text { SE })\end{array}$ \\
\hline 0.5 & - & 70 & $2.3 \pm 0.30$ & $5.7 \pm 0.26$ \\
1.0 & - & 90 & $7.2 \pm 0.24$ & $2.5 \pm 0.34$ \\
2.0 & - & 80 & $3.1 \pm 0.23$ & $3.0 \pm 0.33$ \\
3.0 & - & 75 & $2.8 \pm 0.32$ & $5.1 \pm 0.23$ \\
5.0 & - & 79 & $3.0 \pm 0.25$ & $5.8 \pm 0.24$ \\
- & 0.5 & 60 & $1.8 \pm 0.24$ & $5.7 \pm 0.21$ \\
- & 1.0 & 80 & $2.8 \pm 0.24$ & $1.4 \pm 0.16$ \\
- & 2.0 & 75 & $2.1 \pm 0.27$ & $3.6 \pm 0.26$ \\
- & 3.0 & 70 & $1.7 \pm 0.21$ & $5.1 \pm 0.27$ \\
- & 5.0 & 78 & $1.9 \pm 0.17$ & $3.8 \pm 0.24$ \\
0.5 & 0.5 & 80 & $3.9 \pm 0.37$ & $3.3 \pm 0.26$ \\
1.0 & 1.0 & 85 & $5.7 \pm 0.30$ & $2.7 \pm 0.21$ \\
2.0 & 2.0 & 75 & $2.8 \pm 0.29$ & $4.9 \pm 0.31$ \\
3.0 & 3.0 & 70 & $1.9 \pm 0.23$ & $3.6 \pm 0.22$ \\
5.0 & 5.0 & 72 & $2.2 \pm 0.20$ & $3.5 \pm 0.26$ \\
\hline
\end{tabular}

Data represent an average of three triplicates with ten explants in each $\mathrm{M} \pm \mathrm{S}$.E. 

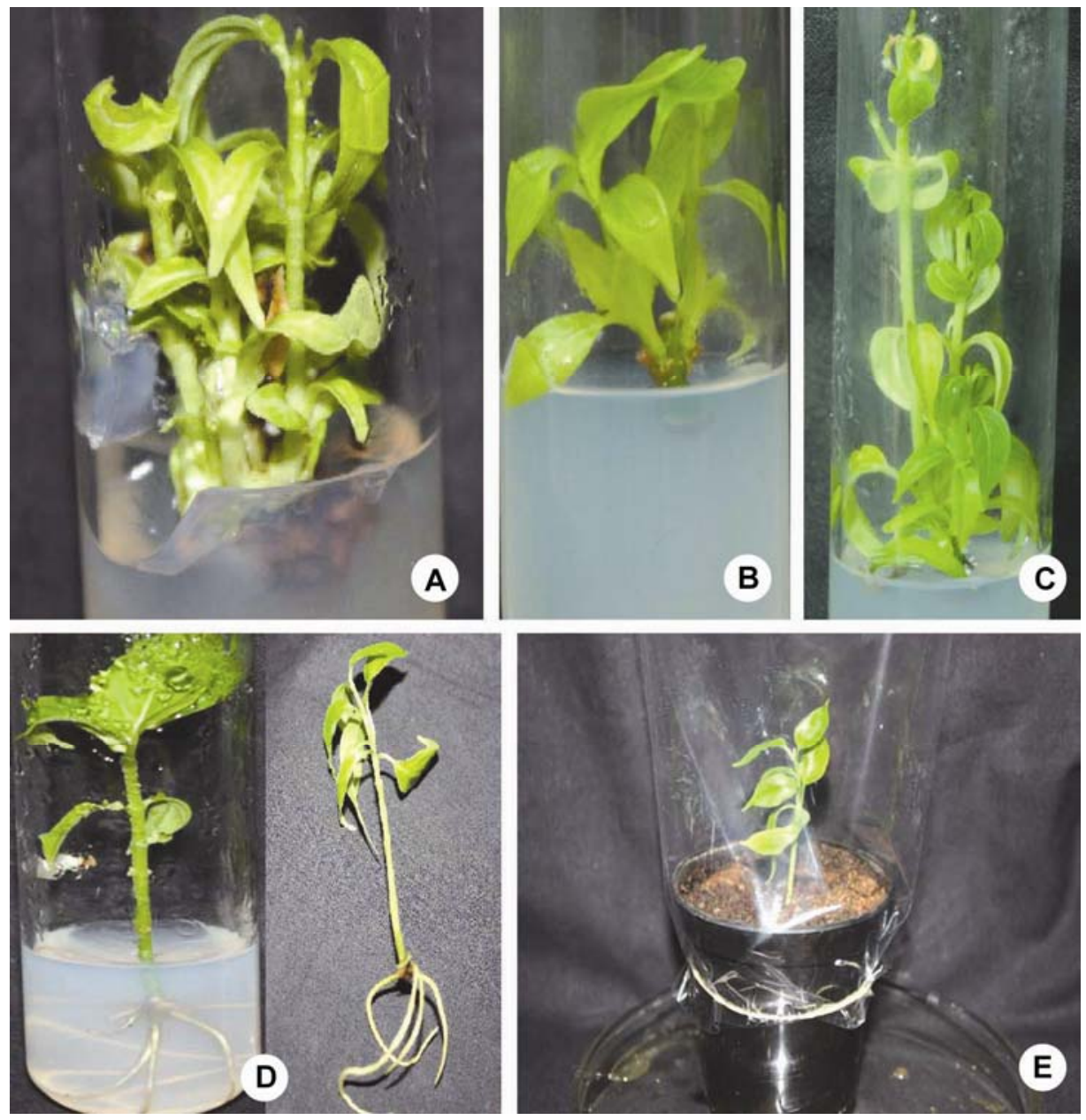

Fig. 1. A. Maximum number of shoot multiplication on MS + BAP $1.0 \mathrm{mg} / \mathrm{l}$. B. Shoot multiplication on MS + Kn 1.0 mg/l. C. Shoot multiplication on MS + BAP + Kn 1.0 mg/l each. D. Root induction on half MS + NAA $0.5 \mathrm{mg} / \mathrm{l}$. E. Plant under acclimation.

When nodal explants were cultured on MS fortified with different concentrations of $\mathrm{Kn}(0.5-5.0 \mathrm{mg} / \mathrm{l})$, only two - three shoot buds were induced (Fig. 1B) as reported in Holostemma ada-kodien (Martin 2002) and Curculigo orchioides (Nagesh et al. 2008).

However, when nodal explants were cultured on MS containing different concentrations of $\mathrm{BAP}+\mathrm{Kn}$ in different combinations for multiple shoot induction, maximum number of (5) shoots were induced on medium containing BAP $(1.0 \mathrm{mg} / \mathrm{l})$ combined with $\mathrm{Kn}(1 \mathrm{mg} / \mathrm{l})$. Whereas, increase in the concentrations of BAP and $\mathrm{Kn}$ decreased the number of shoot buds, this results corroborate with earlier findings in Pedalium murex and Physalis angulata (Ramasubbu 2009). Average length of the shoot buds increased when compared to medium containing BAP or Kn alone (Fig. 1C). 
The present investigation clearly indicates that, among different concentrations and combinations of cytokinins (BAP and $\mathrm{Kn}$ ), BAP alone particularly at $1 \mathrm{mg} / \mathrm{l}$ induced maximum number of shoot buds when compared to either Kn alone or combined with $\mathrm{Kn}$ in different concentrations.

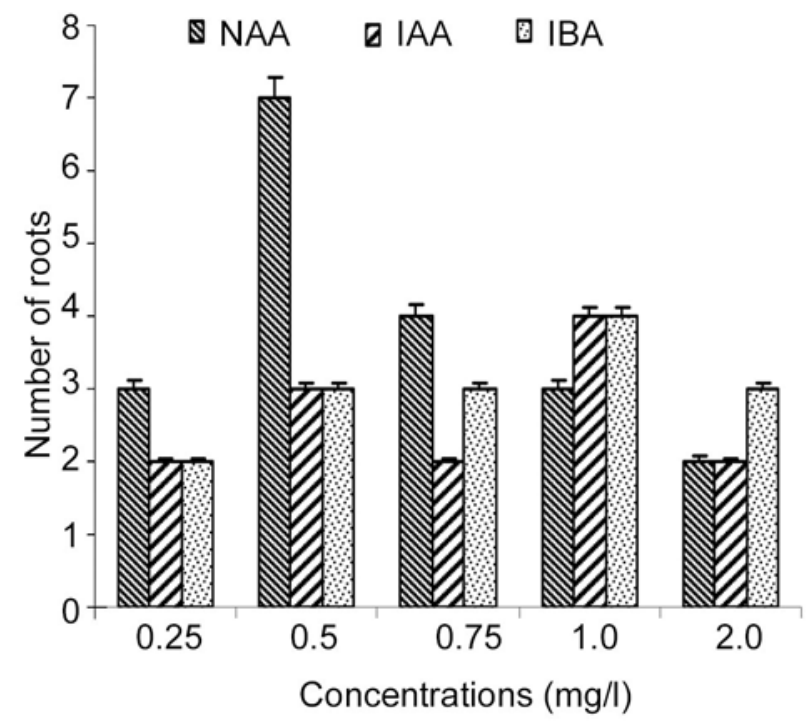

Fig. 2. Effect of different concentrations of auxins on root induction.

In vitro induced shoots were successfully rooted in MS medium supplemented with NAA at strength of $0.5 \mathrm{mg} / \mathrm{l}$. After sequential hardening, the plantlets were transferred to greenhouse where $90 \%$ of them survived. NAA was best for rooting of other Asclepiadaceae members such as three varieties of Caralluma (Aruna et al. 2009) and Ceropegia intermedia (Karuppusamy et al. 2009). Shoots cultured on the medium containing different concentrations of IBA and IAA $(0.25-2.0 \mathrm{mg} / \mathrm{l})$ produced not only a smaller number of roots but also weak shoots.

\section{References}

Aruna V, Kiranmai C, Karuppusamy S, and Pullaiah, T (2009) Micropropagation of three varieties of Caralluma adscendens via nodal explants. J. Plant Biochem. \& Biotech. 18(1): 121-123.

Baytop T, Tanker M, Öner N and Tekman S (1959) Sugars of the glycoside of the root of Marsdenia erecta R. Br. Nature 184: 1319.

Jagtap AP, and Singh NP (1999) Fascicles of Flora of India, Fasclicle 24. Botanical survey of India, Calcutta, India. pp. 124-125. 
Karuppusamy S, Kiranmai C, Aruna V and Pullaiah T (2009) In vitro conservation of Ceropegia intermedia - An endemic plant of south India. African Journal of Biotechnology. 8 (17): 4052-4057.

Komalavalli N and Rao MV (2000) In vitro micropropagation of Gymnema sylvestre - A multipurpose medicinal plant. Plant. Cell. Tiss. Org. Cult. 61: 97-105.

Kottaimuthu R (2008) Ethnobotany of the Valaiyans of Karandamalai, Dindigul District, Tamil Nadu, India. Ethnobotanical Leaflets 12: 195-203.

Martin KP (2002) Rapid propagation of Holostemma ada-kodien Schult., a rare medicinal plant, through axillary bud multiplication and indirect organogenesis. Plant Cell Rep. 21: 112-117.

Nagesh KS, Nayaka HMA, Dharmesh SA., Shanthamma C and Pullaiah T (2008) In vitro propagation and antioxidant activity of Curculigo orchioides. J. Trop. Med. Plants. 9(2): 405-410.

Natarajan D (2004) Identification of conservation priority sites using remote sensing and GIS-A case study from Chitteri hills, Eastern Ghat, Tamil Nadu. Curr. Sci. 86(9): 1316-1323.

Patnaik J and Debata (1996) Micropropagation of Hemidesmus indicus (L.) R. Br. through axillary bud culture. Plant Cell Rep. 15: 427-430.

Ramasubbu, R. (2009) Micropropagation and estimation of biochemical constituents in Pedalium murex L. and Physalis angulata L. J. Sci. Trans. Environ. Technov. 2(4): 226-230.

Sheng-Xiang Qiu, Si-Qi Luo, Long-Ze Lin and Geoffrey A. Cordell (1996) Further polyoxypregnanes from Marsdenia tenacissima (Roxb.) Moon. Phytochemistry 41(5): 1385-1388.

Singhal S, Maheshwari P, Khare, and Anakshi Khare (1980) Tenasogenin, a Pregnane ester from Marsdenia tenacissima (Roxb.) Moon. Phytochemistry 19(11): 2431-2433.

Sreekumar S, Seeni S and Pushpangadan P (2000) Micropropagation of Hemidesmus indicus for cultivation and production of 2-hydroxy 4-methoxy benzaldehyde. Plant. Cell. Tiss.Org. Cult. 62: 211-117. 